\title{
A MUNDIALIZAÇÃO DA CULTURA E OS PROCESSOS DE HOMOGENEIZAÇÃO E FORMAÇÃO DA CULTURA GLOBAL
}

Thatyane Roberta de Castro Costa ${ }^{1}$

Neste artigo, cultura e globalização serão colocadas em perspectiva através da análise das influências e dos questionamentos resultantes da interação entre elas. Irei justificar a importância do aspecto cultural na análise da globalização e as razões de minha escolha por esse campo de estudo em detrimento do econômico. Para tanto, irei definir o que entendo por cultura e destacar suas especificidades que contribuirão para os debates que serão sugeridos. A partir dessas discussões, analisarei o fenômeno da mundialização cultural e os debates de maior relevância sobre globalização e cultura. O primeiro deles trata da existência ou não da formação de um processo de homogeneização cultural global, o qual estaria tornando culturas locais meros obstáculos a serem dominados e sobrepostos pela cultura ocidental, especificamente a norte-americana. $\mathrm{O}$ argumento construído em torno da ocidentalização ou americanização cultural é freqüentemente defendido por ativistas de movimentos antiglobalização $^{2}$. O segundo debate que analiso diz respeito às consequiências acerca da existência de uma cultura global.

O avanço do processo de globalização pode ser considerado como uma das marcas do mundo moderno. Globalizam-se as empresas, os mercados, as economias, etc. O enfoque de algumas análises e discussões sobre globalização enfatiza os campos econômico e financeiro em detrimento dos campos cultural ou social, por exemplo. Segundo essas análises as economias nacionais não sobreviverão isoladas e necessariamente deverão estar em contato umas com as outras, intensificando os fluxos comerciais, financeiros e sociais. Ao

${ }^{1}$ Graduada em Relações Internacionais pelo UniCEUB, no 2o. semestre de 2003.

2 Ver, por exemplo, Naomi Klein. Sem logo. A tirania das marcas num mundo vendido. Rio de Janeiro: Record, 2002.

Universitas - Relações Int., Brasília, v. 2, n.1, p. 255-267, jan./jun. 2004 
agirem dessa forma, irão se enquadrar numa rede de fluxos muito maior: a economia mundial globalizada. Às economias nacionais não restaria opção senão a de agirem dessa maneira nesse cenário.

Segundo Ianni ${ }^{3}$, a globalização tem no capitalismo um de seus desencadeadores, pois reproduz a lógica deste modelo econômico através de um sistema que se baseia na concentração e na produção de mais-valia. Segundo o autor, o capitalismo se desenvolve como um "processo civilizatório universal: compreende relações, processos e estruturas regionais, nacionais e mundiais, envolvendo indivíduos e coletivos, grupos e classes sociais, etnias e minorias, nações e continentes". 4 A atenção dada por Ianni ao aspecto econômico da globalização deve-se também às conseqüências imediatas que tal fenômeno, enquanto manifestação de um processo de avanço do capitalismo moderno, suscita nos críticos deste sistema.

Ianni destaca três razões que o levam a considerar o capitalismo como um processo civilizatório: primeiro, o capitalismo é capaz de integrar espaços, formas de vida e de produção, além de revolucionar continuamente os aspectos sociais, econômicos, políticos e culturais de países não capitalistas ou não-ocidentais; segundo, "cria e recria as forças produtivas e as relações de produção [...] sofisticando a divisão do trabalho social e a especificidade da força de trabalho, informatizando a organização e a atividade econômica, social, política e cultural"5, e terceiro, "o modo capitalista de produção envolve a reprodução ampliada do capital em escala cada vez mais ampla, simultaneamente nacional, continental e global"6. A afirmação acima leva a concluir que, através do desenvolvimento do capitalismo, a globalização, como consequiência desse processo, expandiu-se das áreas de comércio e finanças para áreas de interação social, determinando-as e modificando-as.

As implicações que a abordagem econômica sobre a globalização suscitam não são propriamente seus conteúdos críticos,

${ }^{3}$ Octavio Ianni. Teorias da globalização. Rio de Janeiro: Civilização Brasileira, 1995, p. 53.

${ }^{4}$ Ibidem, p. 53.

${ }^{5}$ Ibidem, p. 53.

${ }^{6}$ Ibidem, p. 53.

Universitas - Relações Int., Brasília, v. 2, n.1, p. 255-267, jan./jun. 2004 
mas a compreensão de que a economia determina todas as formas de vida social. Esta perspectiva contrasta com a tradição antropológica que ressalta que a cultura se mostra um diferente campo da vida em sociedade e não reage da mesma forma que o econômico. Por esta razão não seria possível afirmar que a economia e cultura locais de um país estariam com a mesma intensidade ao processo de globalização e, por conseguinte, que produziriam as mesmas respostas a este fenômeno.

Ainda de acordo com a tradição antropológica, a cultura local não está subordinada às intervenções culturais estrangeiras. Ela é concebida como flexível, adaptável às novidades que a globalização e quaisquer outros movimentos possam trazer por meio de seus fluxos, pois é capaz de englobar novos significados, fatos, imagens de outras culturas sem se contradizer ou perder seu caráter local e suas características essenciais que a diferem das demais formas de vida.

Roque Laraia ${ }^{7}$ ressalta que a cultura influencia e determina até mesmo a esfera biológica das pessoas: a hora de se sentir fome, as doenças que pode "fazer surgir" e até a capacidade de contribuição para a morte de uma pessoa que, sendo excluída e rejeitada de sua comunidade, não vê saídas para fugir desse isolamento social e pode cometer suicídio. É, portanto, fator determinante na organização social de uma sociedade.

É por isso que considerar economia e cultura como campos que atuam - e reagem - de maneira idêntica à globalização não se encaixa ao objetivo deste artigo: problematizar a relação entre globalização e cultura, destacando as características dessa interação principalmente no que se refere aos debates sobre homogeneização e cultura global. Com base nessas razões e por entender que a cultura é o poder primeiro de uma sociedade, uma força que não pode ser retirada ou enfraquecida, é que essas questões serão trabalhadas.

\footnotetext{
${ }^{7}$ Roque Laraia, Cultura: um conceito antropológico. Rio de Janeiro: Jorge Zahar, 1997, p. 77-81.
}

Universitas - Relações Int., Brasília, v. 2, n.1, p. 255-267, jan./jun. 2004 


\subsection{A cultura e suas características}

A partir da contribuição de Geertz ${ }^{8}$ ao estudo sobre cultura, pode-se depreender, tomando a metáfora de Weber ${ }^{9}$, que ela é como um conjunto de teias de significados que o indivíduo constrói durante sua vida. É constantemente relembrada, trabalhada, exercida, modificada, no sentido que é possível incorporar novos conceitos, fenômenos, tecnologias, ou seja, novos elementos à teia. Não se trata, portanto, de algo que tende a se enfraquecer ou que corre o risco de desaparecer com as novidades advindas da globalização, porque a teia de significados, aquele elemento que permite ao indivíduo rir de uma piada ou entender o significado de uma piscadela burlesca, não pode ser transformada em objeto de consumo. Por ser pública, pelo fato de o símbolo e o significado estarem impossibilitados de serem engarrafados ou empacotados e serem expostos em vitrines de shoppings centers, a cultura não está restrita a determinado povo ou sociedade. Indivíduos podem compartilhar signos, símbolos, línguas diferentes, adaptando-os a seu código de atuação.

As culturas locais e globais são uma criação coletiva e anônima e, portanto, de domínio público. A cultura local não é propriedade de alguém, nem mesmo do povo ou do Estado. Tem suas peculiaridades que a diferem das demais culturas, mas é passível de apreensão por aqueles que genealogicamente não fazem parte de determinada tradição cultural.

Ulf Hannerz ${ }^{10}$ ressalta outra característica da cultura: para que se mantenha duradoura, tem de estar em movimento, ou seja, “... as pessoas, enquanto atores e redes de atores, têm de inventar cultura, refletir sobre ela, fazer experiências com ela, recordá-la (ou armazená-

\footnotetext{
${ }^{8}$ Para conceito de cultura em Clifford Geertz, ver "Uma descrição densa: por uma teoria interpretativa da cultura". In: Clifford Geertz. A interpretação das culturas. Rio de Janeiro: Zahar, 1978. p. 13-41.

9 Max Weber. "Conceitos Sociológicos Fundamentais". In: Economia e sociedade. Fundamentos da Sociologia Compreensiva. Brasília, Ed. UnB, 1991.

10 Ulf Hannerz. "Fluxos, fronteiras, híbridos: palavras-chave da antropologia transnacional". In: Revista Mana. Abr. 1997, vol.3, no.1, p.7-39.
}

Universitas - Relações Int., Brasília, v. 2, n.1, p. 255-267, jan./jun. 2004 
la de alguma outra maneira), discuti-la e transmiti-la."11 Isto só é possível porque considerando a cultura como fluxo, o que se "ganha num lugar não se perde na origem"12. Ou seja, o fluxo de pessoas, imagens e significados entre as culturas não as empobrece ou enfraquece: é uma possibilidade de se enriquecer e diversificar distintas maneiras de viver.

Esse é o conceito de cultura trabalhado neste estudo, uma mescla das contribuições de Geertz e Hannerz, que pode ser retraduzido da seguinte forma: cultura é a rede de significados interconectada por cada indivíduo e pelo coletivo que se movimenta por fluxos, portanto, um elemento que não é estático ou eterno, mas que precisa ser constantemente vivido e modificado pelas pessoas.

\subsection{A homogenização cultural e a cultura global}

A questão da mundialização cultural se mostra um interessante ponto de discussão. A globalização trouxe o questionamento do espaço concreto territorializado, já que as distâncias não são mais vistas como fator de isolamento ou impedimento para os fluxos de mercadorias, informação, capital, pessoas. Porém, não é pelo fato de que os contatos desses fluxos estejam muito menos distantes que a globalização esteja produzindo uma cultura homogênea. $\mathrm{O}$ argumento que ressalto é o oposto: a globalização promove diversidade e possibilidades que as culturas locais não experimentariam sem o acesso, por exemplo, à tecnologia, especialmente na área dos meios de comunicações.

Da temática da mundialização da cultura, surge um dos debates mais interessantes no campo de estudo das Relações Internacionais: o de se procurar saber se a globalização resulta ou não em homogeneização cultural. Mike Featherstone tem sido um dos autores ativos nessa discussão. A ele somam-se Arjun Appadurai, Roland Robertson, Boaventura dos Santos, Renato Ortiz, Ulf Hannerz, entre

${ }^{11}$ Ulf Hannerz, op. cit., p. 12.

12 Ibidem, p. 12.

Universitas - Relações Int., Brasília, v. 2, n.1, p. 255-267, jan./jun. 2004 
outros. ${ }^{13}$ Essencialmente são esses os autores que contribuirão para o debate sobre homogeneização versus heterogeneização e cultura global versus cultura local nesta seção.

Antes de avançar na revisão bibliográfica sobre esses debates, entendo por homogeneização cultural o que Featherstone conceitualiza:

"O processo de homogeneização da cultura, o projeto de criação de uma cultura comum, deve ser entendido como um processo [...] da necessidade de ignorar ou, na melhor das hipóteses, de refinar, sintetizar e misturar diferentes locais. [...] O fundamento não é a eliminação das diferenças, os vestígios do regional e das afiliações étnicas locais, mas a percepção do direito do Estado agir assim, o fato de que tais laços são retrógrados, desviantes e precisam ser neutralizados através da educação e dos processos civilizatórios. ${ }^{14}$

Esta é a posição que defendo: a homogeneização da cultura não implica o desaparecimento das diferenças dos hábitos, das necessidades e do consumo das culturas locais, mas, pelo contrário, observa-se a presença de uma heterogeneização de produtos, idéias, imagens, possibilidades trazidas pelo aumento do fluxo entre culturas. A cultura local jamais será massificada porque ela recria significados para serem atribuídos a essas novidades, que podem ser bem diferentes daqueles dados pela cultura que "exportou" esses elementos. Por exemplo, o hip hop importado dos Estados Unidos pelos surinameses não os tornaram iguais aos americanos - e tampouco é essa a intenção deles ao consumirem esse estilo de música. ${ }^{15}$ Pelo contrário, o hip hop

${ }^{13}$ Ver Arjun Appadurai. "Disjunção e diferença na economia cultural global". In: Mike Featherstone (org.). Cultura global. Petrópolis: Vozes, 1994, p. 311-327; Roland Robertson. Globalização: Teoria Social e Cultura Global. Petrópolis: Vozes, 2002; Boaventura dos Santos (org.). A globalização e as ciências sociais. Cortez: São Paulo, 2002; Renato Ortiz. Mundialização e cultura. Braziliense: São Paulo, 1994; Ulf Hannerz. "Cosmopolitas e locais na cultura global". In: Mike Featherstone (org.) op. cit., p. 251-266.

${ }^{14}$ Mike Featherstone. "Cultura global". In: Mike Featherstone (org.). op. cit., p. 142.

${ }^{15}$ Lívio Sansone. "A Produção de uma Cultura Negra: da cultura creole à subcultura negra. A nova etnicidade negra dos jovens creoles surinameses de classe baixa em Amsterdam". In: Estudos Afro-Asiáticos. Rio de Janeiro, n 20, jun. 1991, p. 121124.

Universitas - Relações Int., Brasília, v. 2, n.1, p. 255-267, jan./jun. 2004 
foi reinterpretado e cumpriu o papel de integrador entre jovens surinameses e holandeses em uma sociedade tradicional muito marcada pela representação étnica.

Arjun Appadurai, por sua vez, destaca uma importante característica da relação entre globalização e cultura. Para ele, a globalização não está promovendo uma homogeneização cultural, mas apenas "envolve o uso de uma variedade de instrumentos que são absorvidos na economia e culturas locais sem serem repatriados". ${ }^{16}$

Daí pode-se afirmar que, embora existam de fato culturas que utilizam com maior frequiência meios homogeneizadores ${ }^{17}$ como televisão, marketing e internet para propagarem seus modos de conduta, valores e idiossincrasias, isso não significa que os indivíduos que as absorvam estejam produzindo uma repetição mecânica desses elementos ou dizimando sua própria cultura. E nem se assim desejassem o conseguiriam, pois pelas características da cultura apontadas por Geertz, as trocas não são capazes de tornar culturas distintas em culturas idênticas.

De acordo com o conceito de cultura adotado, é possível posicionar-se frente a uma questão constantemente levantada em assuntos culturais e debate central na temática da mundialização cultural: o atual processo de mundialização da cultura está se direcionando rumo a uma ocidentalização ou americanização global? Por meio da disseminação de valores e símbolos considerados ocidentais e, por vezes, tipicamente americanos, como o individualismo $^{18}$, a democracia política, a racionalidade econômica, estaria ocorrendo uma homogeneização cultural global com base nesses padrões?

Os argumentos de Roland Robertson ${ }^{19}$ ajudam a entender esse processo. O que ocorre nos dias de hoje para o autor não são os

\footnotetext{
${ }^{16}$ Arjun Appadurai, op. cit., p. 312.

${ }^{17}$ Sobre homogeneização cultural, ver Arjun Appadurai, op. cit., p. 311-327

${ }^{18}$ Sobre individualismo nos Estados Unidos, ver Louis Dumont. Homo Hierarchicus. São Paulo: Edusp, 1992 e O Individualismo: uma perspectiva antropológica da ideologia moderna. Rio de Janeiro: Rocco, 1985.

${ }^{19}$ Roland Robertson, op. cit., p. 11.
}

Universitas - Relações Int., Brasília, v. 2, n.1, p. 255-267, jan./jun. 2004 
processos de ocidentalização, americanização ou imperialismo cultural, mas sim a compressão temporal e espacial do mundo como um todo, que reflete a chamada mundialização da cultura. $O$ imperialismo cultural subentende que haja um país que exerça influência sobre a cultura dos demais, um centro difusor de valores, comportamentos e hábitos para o resto do mundo. Por outro lado, a mundialização da cultura é um fenômeno que engloba vários países, num movimento desterritorializado, sem necessariamente haver focos que visem a dominação por meio da influência cultural.

Dessa maneira, a tese da americanização do mundo exige maior aprofundamento. Essa concepção se baseia na história dos Estados Unidos, imaginado como a terra da prosperidade e esperança, democrata e liberal. Trata-se de uma ideologia fortemente eficaz, que permeia o governo, a sociedade, os militares, os empresários, etc. ${ }^{20} \mathrm{~A}$ publicidade condensou esse pensamento e o dispersou pelo mundo. Sua missão era trazer as sociedades "atrasadas" para a modernidade, através do incentivo dos outros a consumirem suas mercadorias e da propagação o American way of life como paradigma a ser seguido.

Para aqueles que apontam para o processo de americanização, existe "uma cultura global sendo formada através da dominação econômica e política dos Estados Unidos, que estendem sua cultura de maneira hegemônica a todas regiões do mundo". ${ }^{21}$ Featherstone destaca ainda que as teorias da modernização e da dependência contribuíram para reforçar a idéia que o imperialismo cultural seria capaz de hierarquizar as culturas locais que, conforme fossem se modernizando, iriam cada vez mais absorver e manifestar a cultura norte-americana. A idéia é que ao Ocidente - leia-se Estados Unidos cabe o papel de "guardião dos valores universais" 22 e a responsabilidade pela difusão desses valores às sociedades mais atrasadas.

Ortiz esclarece que, além da americanização, a tese do imperialismo colabora com esse debate no qual não apenas economia e

\footnotetext{
${ }^{20}$ Renato Ortiz, op. cit., p. 87.

${ }^{21}$ Mike Featherstone. $O$ desmanche da cultura. Globalização, pós-modernismo e identidade. São Paulo: Studio Nobel, 1995, p. 124.

${ }^{22}$ Mike Featherstone, op. cit., p. 127.
}

Universitas - Relações Int., Brasília, v. 2, n.1, p. 255-267, jan./jun. 2004 
política, mas também a cultura, tornaram-se formas de exercício de poder. "Dallas, Disneyland, McDonald's, calças jeans, rock and roll, etc. seriam expressões para uma cultura de exportação". ${ }^{33}$ Segundo essa perspectiva, o resultado dessa cultura de exportação seria o "reforço da dependência política e cultural de outros países em relação aos Estados Unidos e o enfraquecimento das culturas nacionais". ${ }^{24}$

A tese do imperialismo cultural tem a seu favor vários exemplos empíricos. Por exemplo, os Estados Unidos são hegemônicos na indústria cultural, isto é, na produção e distribuição mundial de cinema, publicidade e televisão. ${ }^{25}$ Ortiz afirma que a indústria cultural teria assim fabricado uma cultura irresistível, quase universal, que deveria ser imitada pelos outros, mas com ressalvas, de modo que a identidade americana fosse preservada de imitações incompletas. Mas isto não configura um imperialismo cultural, uma vez que as culturas entram em contato com esses elementos não os copiam simplesmente, mas os reinterpretam e atribuem seus próprios significados a eles, que podem divergir do sentido dado pelos norteamericanos a esses símbolos. ${ }^{26}$

Dessa forma, Featherstone destaca que a mundialização cultural não se resume à generalização porque ela também é capaz de diversificar. Mas importa saber se existe ou não uma cultura global em formação e como ela se configura. Para o autor, é possível pensar em cultura global tomando-se os processos de integração e desintegração cultural trans-sociais em que se baseiam os "fluxos de mercadorias, pessoas, informações, conhecimento e imagens que dão origem aos processos de comunicação e adquirem certa autonomia a nível global". ${ }^{27}$

Ortiz destaca que a formação de uma cultura mundializada não implica o aniquilamento de outras manifestações culturais. Mas o que seria essa cultura mundializada? Estaria o mundo formando uma aldeia global, utilizando o conceito criado na década de 60 por Marshall

${ }^{23}$ Renato Ortiz, op. cit., p. 89.

${ }^{24}$ Ibidem, p. 90.

${ }^{25}$ Ibidem, p. 90.

${ }^{26}$ Renato Ortiz, op. cit., p. 91.

${ }^{27}$ Mike Featherstone, Cultura global, op. cit., p. 7.

Universitas - Relações Int., Brasília, v. 2, n.1, p. 255-267, jan./jun. 2004 
$\operatorname{McLuhan}^{28}$, que elevaria a bandeira da padronização dos hábitos, pensamentos e até necessidades das pessoas?

Há a noção de que o mundo tornou-se um lugar-comum, onde todos interagem com todos, os contatos são maximizados a ponto de formarem uma rede de significados capaz de ser compreendida e vivenciada por todas as culturas, acabando por constituir uma cultura global. Essa cultura de escopo global é a concretização do desejo e necessidade de os Estados compartilharem uma identidade cultural entre eles. Mas a existência de uma cultura que transcenda fronteiras dos Estados nacionais e que gere fluxos culturais a nível global não implica necessariamente um enfraquecimento da soberania, e tampouco representa o início de um processo de perda de soberania generalizada ou a formação de um Estado mundial homogeneizado.

Hannerz acredita que realmente existe uma cultura global nos dias de hoje, uma cultura que está "assinalada por um organismo de diversidade e não por um repetição de uniformidade". ${ }^{29}$ São as culturas locais e suas relações, trocas, contatos cada vez mais acentuados que formam a cultura global. São partes importantes, cada qual com suas particularidades, que formam uma rede de subculturas. Além disso, o autor enfatiza que apesar da existência de uma cultura global, não ocorre atualmente nenhum processo homogeneizador de significados e expressões.

Mas como é possível detectar e perceber a existência dessa rede de significados global? Ortiz ${ }^{30}$ sugere que um caminho possível seja através dos sinais exteriores formados pelas marcas - Coca-Cola, Revlon, Louis Vitton -, ou pelos logotipos, como o "m" amarelo do McDonald's, a estrela da Mercedes-Benz, as listras da Adidas, e ainda pelos produtos diferenciados, como os biscoitos Nabisco, os chocolates Nestlé ou o jeans Levi's. Esses são símbolos identificáveis em praticamente todo o mundo, formam parte da vida cotidiana das pessoas e compõem a familiaridade dos ambientes onde se vive,

${ }^{28}$ Marshall McLuhan; Quentin Fiori. Guerra e paz na aldeia global. São Paulo: Record, 1971.

${ }^{29}$ Ver Ulf Hannerz. "Cosmopolitas e locais na cultura global”, op. cit., p. 252. Grifo meu.

${ }^{30}$ Renato Ortiz, op. cit., p. 107.

Universitas - Relações Int., Brasília, v. 2, n.1, p. 255-267, jan./jun. 2004 
independentemente de onde se esteja. No entanto, há a possibilidade de se observar exemplos da diversidade construída pela globalização e vivenciada pela cultura global através da inserção e adaptação de elementos de outras culturas. Por exemplo, as pessoas podem se sentir "mais globais", ou mesmo pertencentes a essa cultura global, ao acenderem um incenso, terem uma escultura africana, usarem roupas indianas, assistirem a filmes iranianos ou jantarem num restaurante japonês. É essa diversidade de opções que compõe a mundialização cultural e que é compartilhada - e não sobreposta - com os símbolos e significados da cultura local.

$\mathrm{O}$ aspecto primordial de todo esse debate, e que merece ser destacado, é que a crescente troca de significados, símbolos e imagens, impulsionada pela globalização, através dos meios de comunicação, mídia, marketing e moda, é capaz de fornecer novos elementos às redes de significados das diversas culturas que entram em contato com essas novidades. Formam a cultura global e uma rede de significados mundial capaz de ser compreendida por pessoas de vários países, mas que não têm o caráter homogeneizador nessas culturas locais e sim diversificador. Essas redes de significado locais são capazes de reinterpretar as influências trazidas pela cultura global.

Dessa maneira, este artigo dedicou-se a problematizar o fenômeno da mundialização da cultura. Para tanto, definiu o conceito de cultura que melhor se adapta a essa questão e defendeu as espeficidades do campo cultural na relação com à globalização. Os questionamentos relacionados à possibilidade de estar ocorrendo uma homogeneização das culturas nacionais e a formação de uma cultura de escopo global nesse cenário de mundialização cultural foram trabalhados.

O aspecto primordial de na análise da mundialização da cultura e os debates aqui trabalhados é que a globalização promove uma crescente troca de significados, símbolos e imagens, através dos meios de comunicação, mídia, marketing e moda. Esses movimentos são capazes de fornecer novos elementos às redes de significados das diversas culturas que entram em contato com essas novidades. Formam a cultura global e uma rede de significados mundial capaz de ser compreendida por pessoas de vários países, mas que não têm o caráter

Universitas - Relações Int., Brasília, v. 2, n.1, p. 255-267, jan./jun. 2004 
homogeneizador nessas culturas locais e sim diversificador, pois essas redes de significado locais são capazes de reinterpretar as influências trazidas pela cultura global.

\section{Referências Bibliográficas}

APPADURAI, Arjun. "Disjunção e diferença na economia cultural global". In: FEATHERSTONE, Mike. (Org.). Cultura global: nacionalismo, globalização e modernidade. $3^{\text {a }}$ ed. Rio de Janeiro: Vozes, 1990.

DUMONT, Louis. Homo Hierarchicus. São Paulo: Edusp, 1992. . O individualismo: uma perspectiva antropológica da ideologia moderna. Rio de Janeiro: Rocco, 1985.

FEATHERSTONE, Mike. (Org.). Cultura global: nacionalismo, globalização e modernidade. $3^{\text {a }}$ ed. Rio de Janeiro: Vozes, 1990.

$O$ desmanche da cultura: globalização, pós-modernismo e identidade. São Paulo: Studio Nobel, 1995.

GEERTZ, Clifford. "Uma descrição densa: Por uma teoria interpretativa da cultura”. In: GEERTZ, Clifford. A Interpretação das Culturas. Rio de Janeiro: Zahar, 1978.

HANNERTZ, Ulf. "Fluxos, fronteiras e híbridos: palavras-chave da antropologia transnacional". In: Revista Mana. Rio de Janeiro, 1997, v. 3, n. ${ }^{\circ}$ 1, p. 7-39. Também disponível em: http://www.scielo.br/. Acesso em 15 ago. 2003.

"Cosmopolitas e locais na cultura global". In: FEATHERSTONE, Mike. (Org.). Cultura global: nacionalismo, globalização e modernidade. $3^{\mathrm{a}}$ ed. Rio de Janeiro: Vozes, 1990.

IANNI, Octavio. Teorias da Globalização. Rio de Janeiro: Civilização Brasileira, 1995.

KLEIN, Naomi. Sem logo: a tirania das marcas em um mundo vendido. Rio de Janeiro: Record, 2002.

LARAIA, Roque de B. Cultura: um conceito antropológico. Rio de Janeiro: Zahar, 1986.

MCLUHAN, Marshall. FIORI, Quentin. Guerra e paz na aldeia global. Rio de Janeiro: Record, 1971.

Universitas - Relações Int., Brasília, v. 2, n.1, p. 255-267, jan./jun. 2004 
ORTIZ, Renato. Mundialização e cultura. $3^{\text {a }}$ ed. São Paulo: Brasiliense, 1994.

ROBERTSON, Roland. Globalização: Teoria Social e Cultura Global. Petrópolis: Vozes, 2002.

SANSONE, Lívio. "A produção de uma cultura negra: da cultura creole à subcultura negra. A nova etnicidade negra dos jovens creoles surinameses de classe baixa em Amsterdam". In: Estudos Afro-Asiáticos, Salvador, n 20, p. 121-124, jun. 1991.

SANTOS, Boaventura. A globalização e as ciências sociais. Cortez: São Paulo, 2002.

WEBER, Max. "Conceitos sociológicos fundamentais". In: Economia e sociedade. fundamentos da sociologia compreensiva. Brasília: Ed. UnB, 1991.

Universitas - Relações Int., Brasília, v. 2, n.1, p. 255-267, jan./jun. 2004 